\title{
De pedagogische begeleiding van jonge mensen op een gedenkplaats
}

Tussen participatie en competentiesturing in Neugengamme

Iris Groschek

Traducteur : Rita Roggen

\section{(2) OpenEdition}

1 Journals

\section{Édition électronique}

URL : https://journals.openedition.org/temoigner/7285

DOI : $10.4000 /$ temoigner.7285

ISSN : 2506-6390

\section{Éditeur :}

Éditions du Centre d'études et de documentation Mémoire d'Auschwitz, Éditions Kimé

\section{Édition imprimée}

Date de publication : 2 avril 2018

Pagination : 84-90

ISBN : 978-2-930953-06-9

ISSN : 2031-4183

Référence électronique

Iris Groschek, «De pedagogische begeleiding van jonge mensen op een gedenkplaats», Témoigner. Entre histoire et mémoire [Online], 126 | 2018, Online op 24 janvier 2022, geraadpleegd op 04 février 2022. URL: http://journals.openedition.org/temoigner/7285 ; DOI: https://doi.org/10.4000/temoigner. 7285 


\section{De pedagogische begeleiding van jonge mensen op een gedenkplaats Tussen participatie en competentiesturing in Neugengamme}

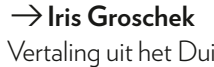

Rita Roggen

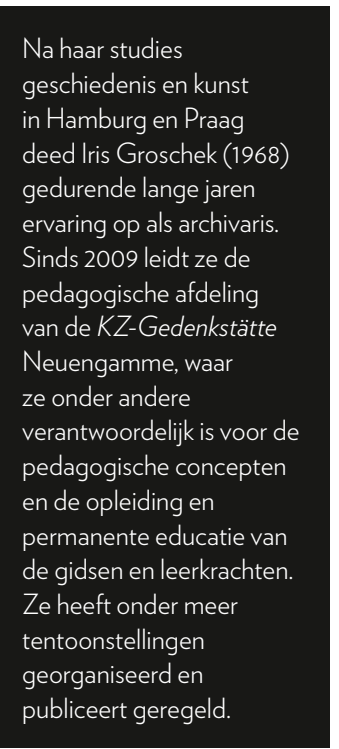

\section{SOORTEN BEZOEKERS, MOTIVATIE EN KENNIS}

k werk op de KZ-Gedenkstätte Neuengamme in Hamburg, een plek dus, waar tijdens het nationaalsocialisme onrecht werd aangedaan aan 100000 mensen. Mensen uittalrijke Europese landen, dievooral voor politieke en racistische redenen werden gevangen ${ }^{1}$ Deze , distische redenen werden gevangengezet. 'Deze plaats maakt indruk. I w wi het niet authenticiteit noemen, want na zeventigjaar is deze plek niet meer authentiek. Maar toch maakt ze vanaf de eerste stap indruk op de individuele bezoeker, wegens de kenni die de bezoekers meebrengen. Die kennis over de gebeurtenissen in de concentratiekampen is vaak beïnvloed door media, foto's, films en boeken. Maar wat weten bezoekers precies over de geschiedenis van deze plek, over het concentratiekamp van Neuengamme, als ze naar ons komen? Ik durf te beweren dat het vaak heel weinig is

Dat brengt ons tot de volgende vraag: wat willen de bezoekers door het bezoek aan de gedenkplaats van het concentratiekamp beleven? Wat verwachten ze? Willen ze wel iets beleven? Misschien iets nieuws, misschien iets dat choqueert of irriteert? Of heeft een bezoek aan de gedenkplaats van een concentratiekamp een andere functie? En waar zijn de rakpunten met dat wat wij als gedenkplats aan andere fij de raakpunten met dat wat wij als gedenkplaats aan kennis willen overleveren? Wat kunnen wij doorgeven? Wat blijft er van de didacche doelstellingen werkelijk hangen?

Het soort bezoekers dat naar gedenkplaatsen komt en dus de reden voor het bezoek zijn de laatste jaren veranderd en verruimd. Voor Neuengamme geldt algemeen dat individuele bezoekers internationaler zijn geworden, dat het vooral toeristen zijn en dat schoolklassen de tendens vertonen jonger en heterogener te zijn en doorgaans minder gemeenschappelijke, consensuele voorkennis meebrengen. Ik vraag me af of gedenkplaatsen bij hun opleidingswerk genoeg rekening houden met de verschillende cognitieve en emotionele achtergrond, de kennis, de culturele bagage en het narratief. Neem nu de verschillende groepen van bezoekers: familieleden rezinnen internationalegroenenenindividuelebezoekers khssenuthetbijzonder den, gezinnen, internationale groepen en individuele bezoekers, klassen uit hetbijzonde onderwijs, vormelingen, bezoekers uit Hamburg, toeristen van cruiseschepen, laatste-
jaarsleerlingen, onthaalklassen (vluchtelingen), bedevaartgangers, laatstejaarsstu- denten, inclusieklassen, groepen met een beperking, militairen, beroepsgroepen, Dark Tourists, mensen met belangstelling voor de geschiedenis, nieuwsgierigen.. Alleen al deze onvolledige opsomming toont aan dat niet enkel de reden voor het bezoek, maar ook de benadering en de wijze waarop kennis wordt vergaard, sterk verschillen. Dat resulteert in zeer uiteenlopende verwachtingen en wensen met betrekking tot het bezoek, die telkens weer een andere vorm van begeleiding vereisen. Ik wil namelijk iedereen die beslist de gedenkplaats van een concentratiekamp te bezoken, serieus nemen. Mensenvertoevenzelden toevaligop dezeplek, eerder bewust, ook al is het niet altijd vrijwillig (bijvoorbeeld een klasbezoek).

Waar begint de pedagogische begeleiding? Waar begint historisch-politieke opvoeding? Waar begint iemand na te denken over zijn ideeën en ze in vraag te stellen? Het antwoord schijnt in eerste instantie eenvoudig. Ik moet mijn gesprekspartner bereiken om effect te sorteren, en eenzijdig informatie zenden volgens de klassieke leraar-leerlingrelatie is niet duurzaam. Ik wil eerder een uitwisseling bewerkstelligen. Volgens mij is het communicatieve aspect van de pedagogische begeleiding het belangrijkste. Enkel via dialoog zullen mensen hun eigen kennis en (voor)oordelen bevragen, en in het beste geval dieper gaan nadenken over bepaalde kwesties. Daarom moet de gids-begeleider bij het uitoefenen van zijn of haar taak in eerste instantie open staan voor de bezoekers.

Natuurlijk is het mijn rol als begeleider om een connectie te maken tussen kennis in verband met een concrete plek en een concrete gebeurtenis, en die vervolgens door te geven. De historische plek staat voor de gebeurtenis. Om deze plek echter te kunnen decoderen is de hulp vereist van de pedagogisch begeleider. Deze plek is nu eenmaal niet meer authentiek, maar heeft een andere gestalte gekregen, heeft een symbool- en appelfunctie en is zakelijk en kaal. Om dan niet over het hoofd van de mensen te praten moet je proberen om via de kennis die ze zelf aanbrengen een gesprek aan te knopen, en voorstellen om deze kennis te toetsen of, afhankelijk van de reden van het bezoek, eerst en vooral te proberen de nieuwsgierigheid te prikkelen om zo openheid voor de plek te creëren Ook hier is het cruciaal dat debezoekerwordt betrokken. Wanneer ik an jongeren denk, betekent dat geen te hoge eisen stellen, maar ook niet moraliseren. Pas wanneer je gesprekspartners tijdens de rondleiding de indruk hebben dat ze serieus worden genomen, staan ze open voor de verhalen over de plek, kunnen ze onbevooroordeeld luisteren of zullen ze zich persoonlijk verdiepen in de zaak. Concreet betekent dit dat ik als begeleider communicatie op verschillende niveaus moet aanbieden, om precies de verschillende soorten mensen te bereiken die Neuengamme komen bezoeken.

COMMUNICEREN IN DE VIRTUELE WERELD

Overlevering is voor mij ook de aanwezigheid op de sociale media (vgl. Groschek \& Schoder 2017). Op het wereldwijde web kunnen we verhalen vertellen, zodat de herinneringsplek zichtbaar wordt voor wie die zelf niet kan bezoeken of pas via het internet leert kennen. Daarom zijn concentratiekampen zoals het Auschwitz-memo-
(1) Er waren ook
50 Luxemburgers. Luxemburgse gevangenen politieke gevangenen. Ze warmen
o.a. lid van de Luxemburgse vrijwilligerscompagnie. Minstens zeventien van hen hebben het
concentratiekamp Neuengamm niet overleefd. Het dossier
Gevangenen uit Luxemburs Gevangenen uit Luxemb
in het concentratiekamp Neuengamme' kan ook in het kader van de online
tentoonstelling van de $K Z$. Gedenkstätte Neuengamme op www.neuengamme-ausstellungen. info worden bekeken. Directe link: http: ///Www.neuengamm
ausstellungen.info/content/ documents/thm/ha2_2_4_3 
De pedagogische mensen op een gedenkplaats mensen op een gedenk
Tussen participatie en competentiesturing in Neugengamm

riaal of wij als Neuengamme-memoriaal actief op twitter, Facebook en Instagram. ${ }^{2}$ Wij spreken daar uiteenlopende communities met een uiteenlopende content aan $\mathrm{Ja}$, ook de fotocommunity Instagram. Foto's van het Auschwitz-memoriaal werden daar in 2016213000 keer geliket. De gedenkplaats beschouwt elke like als een $I$ remember en ziet de activiteit van gedenkplaatsen op de sociale media als virtual community of remembrance. ${ }^{3}$ Omdat ook foto's een concept van herinnering bevatten - op onze account voorzien wij elke afbeelding van verhalen, herinneringen of verwijzingen - zie ik deze lagdrempelige toegang a vorm van over . Bovendienvertelendefoto's ie door anderen op de sociale media worden gepost, zeer veel over de manier waarop bezoeker onze gedenkplaats waarnemen, hoe ze de plek zien, of - en dat is nog interessante - hoe ze de plek met behulp van beelden construeren. En zo oefenen ze met hun foto's invloed uit op de manier waarop anderen op hun beurt de site waarnemen. Ook deze beelden drukken dus een stempel op de gedenkplaatsen. Ik geloof dat het belangrijk is om daar nota van te nemen, en die externe vorm van overleverings- en herinneringswerk te waarderen. Enkel wanneer ik weet wat bezoekers meenemen, kan ik immers mijn opvoedingswerk met rondleidingen, vaste tentoonstellingen en onderzoek afstemmen op datgene wat maatschappelijk relevant is

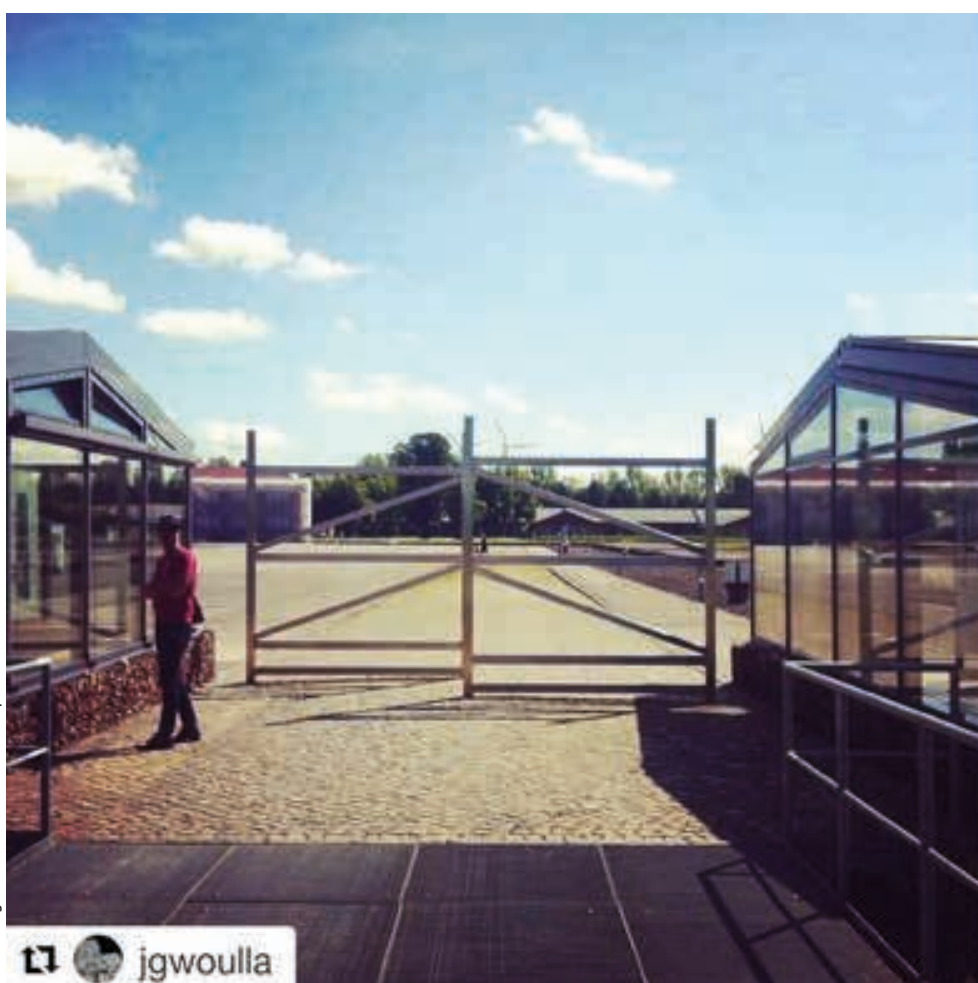

neuengamme-memorial : Follow

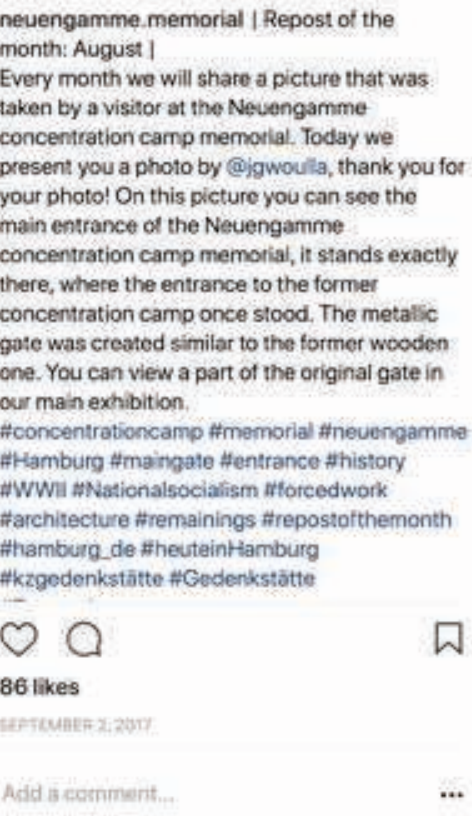

Daarnaast vind ik het uitermate belangrijk dat de gedenkplaatsen van concentratiekampen aanwezig zijn in de virtuele wereld en op die manier een bewuste betrouwbare tegenpool vormen voor niet gefundeerde meningen of zelfs hatespeech. Het volstaat ervoor te zorgen dat de gedenkplaats in verschillende zones van het internet kan worden gevonden. De eigen homepage moet daarbij referentie- en uitgangspunt zijn. Onze homepage heeft bijvoorbeeld een blog waarop wij kleine mededelingen en aankondigingen plaatsen. Wij moeten echter ook actief zijn op de sociale media en dar zowel virtuele als toekomstige reäle bezoekers aanspeken (a) door bijvoorbeend onze formats - geleide aan te kondgen, door vorijnwerpers te plaatsen, door te vertellen wat \#otd (on this day) 70 of 75 jaar geleden is gebeurd, door mee te delen wie ons bezoekt en waarom (op twitter publiceerden we bijvoorbeeld commentaren van deelnemers aan ons zomerwerkkamp), door actuele onderzoeksprojecten te beschrijven, door onze stagiairs objecten te laten voorstellen die in tentoonstellingen aan bod komen en een persoonlijke betekenis voor hen hebben. Naar aanleiding van de zeventigste verjaardag van de bevrijding hebben we de herdenkingsviering live gestreamd, zodat bijvoorbeeld familieleden en overlevenden die niet aanwezig konden zijn, er online toch bij waren ${ }^{5}$ Virtuele contacten leiden bovendien totconcrete ontmotingen ter platse ik $\mathrm{s}$ The $\mathrm{k}$ bied Tweetalks an, waarbij de smartphone actief wordt ingezet. Dat klinkt misschien wat luchtig, misschien zelfs ongepast, maar strikt genomen is het ook
'maar' een communicatiemethode en een gespreksbasis (Groschek \& Jost 2016).

\section{PARTICIPEREN EN ONDERZOEKEND LEREN}

Het gebruik van een smartphone lijkt misschien wel modern, maar bij het dageijkse begeleidingswerk met scholen speelt die eerder een ondergeschikte rol. Bij een bezoek is het dan weer anders. Wij bieden scholen een webapp aan waarop wij kort voormalige gevangenen voorstellen die om verschillende redenen vervolod werden ${ }^{6}$ Hun verhalen moeten leerlingen vooraf an werden. Hun verhalen eren. te gebruiken, dat gebeurt alleen in het kader van projectdagen. In Neuengamme bieden wij een app aan die informatie verstrekt over 113 etappes van het terrein. ${ }^{7}$ Deze app werd ontwikkeld om individuele bezoekers te helpen om het enorme terrein te reconstrueren, maar ook tijdens de projectdag 'Op zoek naar sporen' met een schoolklas kan het gebruik van de app zinvol zijn. Op die manier doorbreken we de klassieke verwachtingen van de groep met betrekking tot een rondleiding met een gids, wanneer ze in eerste instantie in kleine teams het terrein verkennen. Met behulp van historische foto's gaan ze op zoek naar de plek zoals die er nu uitziet. Ze hebben samen een foto gekozen, en zo onbewust ook al een thema bepaald. Met de hulp van de app inforn hulp vande app ifort (a) dan voor gevangenen kon hebben gehad of welk thema door deze plek het sterkst facebook.com/Neuengamme
Memorial; Twitter: http:// twitter.com/GedenkstaetteNG com/neuengammememorial

(3) Commentaar bij de Instagrampost van het Auschwitz-
memorial (http://www.instagram. 30 december 2016 .

(4) Met betrekking tot het thema Instagram op gedenkplaatsen, zie
Steffen Jost \#ddarfmonsowasposte otografische Reprassentationen al media en herinneringsculturen' op het congres Erinnerr Kontrovers . (5) Nog te bezichtigen via onze
Vimeo-account: https://vimea com/neuengammememorial. (6) www.kz-gedenkstaetteNeuengamme' op Googleplay 
wordt gesymboliseerd. De onderzoeksvraag van een team bij de wagon kan bijvoorbeeld zijn wat de aankomst in het concentratiekamp voor de mensen betekende. Het team kan echter ook heel andere thema's en vragen uitkiezen. Aansluitend op de verkenningstocht gaan de verschillende teams 'hun' thema verder onderzoeken in de tentoonstellingen en stellen ze het voor aan de volledige groep tijdens de afsluitende gemeenschappelijke rondgang. De begeleider stelt vragen, of helpt moeilijkere vragen te beantwoorden.

Bij een dergelijke projectdag is het onze bedoeling dat leerlingen specifieke competenties ontwikkelen: zich thema's eigen maken, beslissingen treffen en resultaten voor stellen. De begeleider gaat niet zozeer een uiteenzetting geven, maar eerder helpen om documenten, objecten of biografieën te vinden die een antwoord kunnen bieden op de vragen van de groep. Onderzoeksvragen waarnaar persoonlijk onderzoek werd verricht, zijn prominenter aanwezig, leiden tot vragen en in het ideale geval tot zelfstandige reflectie over een thema Daarom bestat deze methode vanon deze terrein, mar ook op de terrein, maar ook op de projectdas 'Gegenstandsgeschichten' (Verhalen over objecten). Leerlingen mogen originele objecten betasten, erover nadenken. En dat is fascinerend, of ligt op zijn minst buiten de verwachtingen. Voorwerpen dienen als basis om een thema te vinden en stimuleren vrijwel meteen de formulering van vragen.

Deze activering boekt ook succes Deze activering boekt ook succes bij eenvoudige rondleidingen. De challenge of interaction van de gedenkplaats Mauthausen heeft ons gestimuleerd om een rondleiding in de vorm van een dialoog te ontwikkelen (Brachmann, Lapid \& Schmutz 2014). De dialoog kan de bezoeker helpen om zich actief te verdiepen in de thema's van de plek. Als impuls werden er op de verschillende etappes visuele en haptische stimuli voorzien. Onder begeleiding kunnen bezoekers de resten of de voorstellingen van historische gebouwen in detail bekijken. Automatisch rijzen daarbij niet enkel vragen en bedenkingen met betrekking tot de functie maar ook de voorstelling of (ontbrekende) recon vraagt om te worden ontcijferd. Een andere impuls is een voorwerp dat aan de
etappe wordt overhandigd. De leerlingen zijn nieuwsgierig, stellen meteen zelf metheren niet reconstructie ${ }^{8}$ Er zym heel wat symbolische voorstellingen en deze symboliek vragen over het voorwerp zonder dat ze moeten worden aangespoord ze lezen wat aangespoord, ze lezen wat er dient te worden ontcijferd,

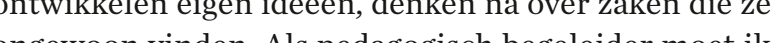
ongewoon vinden. Als pedagogisch begeleider moet ik bij deze etappe enkel wachten, het voorwerp als stimulus gebruiken en de vragen beantwoorden. In feite vertel ik ben geleden, alleen vertel ik ze niet prospectief, maar als antwoord op een concrete vraag. Op die manier bereik ik de deelnemers makkelijker op een rondleiding die niet de bedoeling heeft een rondleiding te zijn, maar eerder een gesprek tussen gelijken.

De pedagogische begeleiders hebben nog steeds een

(a) keuze worden maar licht gewijzigde rol. Voor elke rondleiding kan en moet er een aan onderwen gemaakt tussen de plaatsen en thema's die samen een groot spectrum kunstom inform omvatten. Bij pedagogische projecten op gedenkplaatsen is het de groep. Je fungeert als tus de plaats met de hulp van een gids over te breng wil, dat wat de gids weeten wil, en wathet terrein a metafoor eveneens weeten wil (of: prijsseeft). Begeleiding in concentratiekampen is dus specifiek voor elke plaats, deelt kennis en activeert in de zin van de historisch-politieke opvoeding. Voorwer-

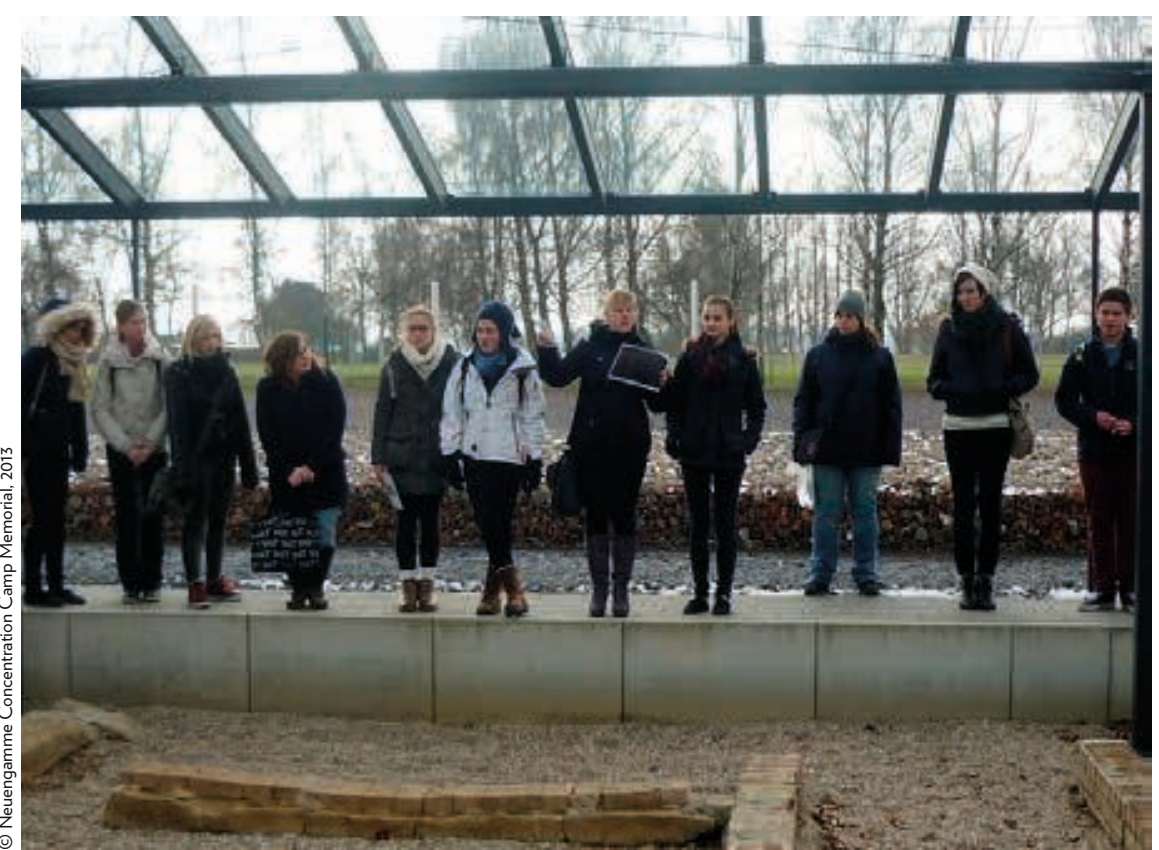
dezelfde verhalen over de mensen die op die plaats heb-
- Een groep leerlingen voert onderzoek tentoonstellingsruimte.
(8) In de Gedenkstät 17 originele gebourwen, maar vele bezoekers verwachten zolve qua boummateriaal
als op grond van het andere gebruik van het gebouw ne zijn geen heropgebouwde
nieuwgebouwde barkken. 
De pedagogische

begeleiding van jonge

mensen op een gedenkplaats:

Tussen participatie en

competentiesturing in

Neugengamme

(vervolg)
(9) Wie wollt ihr euch erinnern? Documentatie van het participatieproject voor jongeren aan de conceptionele ontwikkeling van het informatieen documentatiecentrum Hannoverscher Bahnhof. Hamburg 2012.

\section{BIBLIOGRAFIE}

- Iris Groschek \& Angelika Schöder, 'Zwischen Tweetup und \#yolocaust: Social Media als Herausforderung für Gedenkstätten', Musermeku, http://musermeku.org/2016/01/27/ zwischen-tweetup-und-yolocaust, 2017 (geraadpleegd 29 januari 2018).

- --- \& Steffen Jost, 'Tweetup und Memorialwalk. Social Media in der Vermittlung an Gedenkstätten', Lernen aus der Geschichte, 2016, lernenaus-der-geschichte.de/Lernenund-Lehren/content/13114 (geraadpleegd 29 januari 2018).

- Ines Brachmann, Yariv Lapid \& Wolfgang Schmutz (red.), The Challenge of Interaction. Developing Education at Memorial Sites, Bregenz, 2014, https:// www.mauthausen-memorial.org/ assets/uploads/Brachmann_ Lapid_Schmutz_Challenges-ofinteraction.PDF (geraadpleegd 29 januari 2018). pen, overblijfselen en afbeeldingen zijn over het algemeen belangrijke instrumenten bij de overleving van geschiedenis. Tenminste, wanneer die niet als illustratie, maar als gespreksbasis worden beschouwd, omdat ze verschillende aanknopingspunten voor verschillende groepen bieden. Voorwerpen kunnen door veel deelnemers uit de groep worden uitgelegd, ook door degenen die geen uitgebreide leescompetenties bezitten, of geen gemeenschappelijke taal spreken, of slechts beperkte voorkennis over het nationaalsocialisme hebben en dus ook citaten veel moeilijker zouden begrijpen. Zij krijgen dus, net als alle andere deelnemers, de mogelijkheid hun eigen kennis met de groep te delen.

\section{HERINNERINGSPEDAGOGIE IN DE TOEKOMST}

Participatie werkt op kleine schaal, bij elke rondleiding, met de meest uiteenlopende groepen. Ook al verschillen de gesprekken die ontstaan, de methode is steeds dezelfde. Natuurlijk werkt participatie ook op andere niveaus. Een van onze projecten had de naam 'Welke herinneringen willen jullie?' Jongeren werden uitgenodigd om ideeën te ontwikkelen voor een nieuwe toekomstige gedenkplaats in Hamburg: het voormalige deportatiestation, van waaruit 8000 mensen (Joden, Roma en Sinti uit Hamburg en Noord-Duitsland) naar de getto's en vernietigingskampen van Oost- en Midden-Europa werden gedeporteerd. De jongeren uitten duidelijk hun mening over hoe een dergelijke gedenkplaats er moet uitzien, om ook toekomstige generaties bewust te maken van het belang van kennis over de motieven en de gevolgen van het nationaalsocialisme. Ze discussieerden met overlevenden, deden onderzoek, zagen connecties met de actualiteit en ontwikkelden heel concrete ideeën. Die beantwoordden niet altijd aan de verwachtingen van de stuurgroep van het project, maar kwamen heel spontaan en gaven een goed beeld van hoe, volgens de jongeren zelf, een jeugdig publiek bereikt kon worden. ${ }^{9}$ Hun input met betrekking tot het project en de tentoonstelling zal worden geïntegreerd in de toekomstige gedenkplaats.

Als je mij dus vraagt in welke richting zich het pedagogische werk op de gedenkplaatsen van concentratiekampen ontwikkelt, is het antwoord dat de verhalen van de slachtoffers ook in de toekomst moeten worden doorverteld. Dat we over de redenen moeten spreken die ertoe hebben geleid dat concentratiekampen werden opgericht, hoe het kan zijn dat zovele mensen dit systeem hebben ondersteund. Precies in de huidige tijd moeten we daarover spreken, een tijd waarin racistische, antisemitische, uitsluitende en boze stemmen zo luid klinken. Wij moeten vandaag echter ook andere aanknopingspunten met de geschiedenis zoeken. Laten we het aandurven om te luisteren en te discussiëren over andere verklaringen. Laten we niet ophouden met actief op te treden en zo de relevantie van onze zaak in de maatschappij duidelijk te maken. Niet alleen ter plaatse op de gedenkplaats, maar ook op het internet, in samenwerking met jonge mensen, tijdens seminaries met familieleden van de tweede, derde of vierde generatie, via beroepsspecifieke projecten, via nieuwe aanwinsten en methodes. Via het gesprek. 